\title{
Development Stages of Intelligent Parking Information Systems for Trucks
}

\section{Zsolt Péter Sándor, Csaba Csiszár}

Budapest University of Technology and Economics (BME), Faculty of Transportation Engineering and Vehicle Engineering, Department of Transport Technology and Transport Economics Müegyetem rakpart 3, H-1111 Budapest, Hungary E-mail: sandorzs@kku.bme.hu, csiszar@kku.bme.hu

\begin{abstract}
The route planning of trucks also includes the planning of the parking. Research has already shown that parking demands often exceed capacities. This problem can be managed by appropriate information provision. It is also discussed by European strategic documents, the ITS Directive and the ITS Action Plan, as a priority assignment. Advanced intelligent parking management systems for trucks, planned and partially installed ones, provide real-time information and central (system optimum based) navigation with automatic parking place booking. In this way, the capacity utilization of parking facilities can be maximized. Nowadays such complex systems are still not available, only some partfunctions, but modern information and communication technology offers new opportunities in transportation applications. The article classifies the parking information systems into five plus one (5+1) service levels according to their functions. On the highest service level, the information system offers individual route plans for every user while it takes drivers' working hours, actual traffic conditions and personal preferences into consideration. In the future, mobility and parking demands can be influenced by real-time and interactive information management.
\end{abstract}

Keywords: intelligent truck parking; integrated information system; parking management; navigation; intelligent transport systems and services

\section{Introduction}

The route planning of trucks includes also planning for parking. As a result, detailed route plans of vehicles are determined according to their departure place and time, as well as to the destination and the scheduled time of arrival. Route plans contain scheduled stops, too. Intermediate halts are specified by European rules and regulations [8]. Truck drivers spend this mandatory time at parking facilities located along the motorways. 
Parking demand usually exceeds capacity. The aim of the intelligent parking information system (which is a part of ITS services, i.e., intelligent transport systems) is to maximize the capacity utilization of the limited available parking spaces by coordination of parking demands and capacities. The services of complex information systems go beyond parking management, and they realize network management functions, too.

\section{Intelligent Parking Management for Trucks}

Intelligent parking management systems are new not only in Hungary but also in Europe, and they have high priority [1], [3]. Management services combine:

1. Information provision about parking facilities and free capacity,

2. Complex route guidance and

3. Preliminary parking place booking.

Services are available pre-trip and on-trip through different communication channels. Systems can provide individual (personalized) and collective information.

In this way, it is possible to avoid utilization over $100 \%$ caused by irregular parking when a few kms away facilities are unexploited in space and time. This phenomena may have several causes [6], [7], [10], [11]:

- Truck drivers do not have any information about actual occupancy, services and locations of the next few facilities;

- Some of the parking places do not meet the basic requirements (safety, security, sanitary facilities and restaurants, etc.);

- $\quad$ Experience shows that in the case of no free parking places, drivers would rather park in a dangerous, not designated area of an already full truck park than pass on and break the rules of the obligatory rest time.

Preliminary parking space booking supports the work of truck drivers and dispatchers of haulier companies.

Effects of the service [2], [4], [5]:

- Safety: parking in dangerous and not designated areas (due to congestion) can be avoided. Drivers can have rest in time, taking rules and regulations into consideration. Secure parking places protect the cargo against vandalism and theft.

- Network efficiency: Capacity utilization can be maximized and unnecessary traffic searching for parking places can be decreased. With the use of real-time traffic data, route guidance becomes more efficient and more comfortable. Thus, congestions can be avoided. 
- Environmental impact: As a consequence of the above, air pollution can be mitigated. With optimal capacity exploitation there is no need for new infrastructure.

- Decrease in operational damages: The amount of infrastructure damage can be decreased.

In regions and/or cities where mobility management is well-developed, operators of parking facilities exploit the potential of smartphones and the internet. They can do it independently or jointly. Websites and smartphone applications (route planning and information provision applications) have been developed. With these applications, users can select facilities, they can browse static and dynamic information, and they can pre-book parking lots.

The penetration of smartphones provides a new information provision platform for system developers and service providers, especially in the matter of individual information. Data exchange protocols of on-board navigation systems provide the opportunity to transmit parking information data through RDS-TMC ${ }^{1}$ and TPEG $^{2}$. Pre-booking of parking places has already been available in some pilot projects and it can be presumed that new projects will also be launched in the near future.

Safe and secure parking does not belong closely to the core domain of parking management systems. However, this topic is also a high priority because $60 \%$ of the road transport attacks occur in unguarded parking places. The value of these damages is about 8 billion Euros per year [12].

\section{Levels of the Parking Management Systems}

Parking management systems can be classified by their functions and operations. In the following, a classification containing $5+1$ categories (service levels) is been presented. Service levels - according to solutions with different information provision and different intervention functions - are built up modularly. The lower level services are supplemented by additional services at the higher levels. Fig. 1 illustrates the structure of levels. Level "0" can be separated from the dynamic parking management systems.

$1 \quad$ Radio Data Systems - Traffic Message Channel: technology for delivering traffic and travel information to motor vehicle drivers

2 Transport Protocol Experts Group - They developed the TPEG specifications for transmission of language independent multi-modal Traffic and Travel Information. TPEG data are human understandable as well as machine readable. 


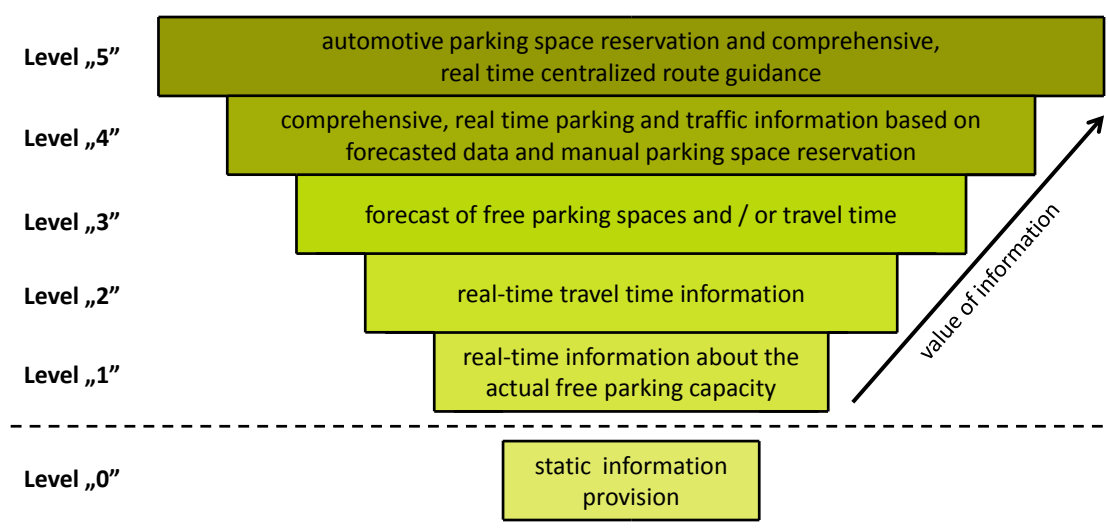

Figure 1

Classification of service levels

Table 1 illustrates the functions and features of each service level based on leading European examples. Currently, the applied parking and information management systems can be categorized into Level "0" to Level "4".

As a consequence of new technologies, the management of traffic data has become much more integrated. The roles of traffic management centres are being revaluated and their functions extended. Central, interactive (two-way communication), integrated, real-time navigation solutions have increasingly come increasingly into praxis. These new solutions enable system optimum based traffic control, which provides smooth and maximized capacity utilization of parking facilities, while also taking users preferences into consideration.

The growing penetration of mobile communication and mobile internet is resulting in the development of new applications that can be used in the transport sector. Thus, the route planning procedures of haulier companies are changing.

The features of the certain service levels have been summarized. Figures illustrate the top level functions. 
Table 1

Service levels of parking management systems (functions and features)

\begin{tabular}{|c|c|c|c|c|c|c|c|}
\hline & & Level "0" & Level "1" & Level "2" & Level "3" & Level "4" & Level "5" \\
\hline \multirow{4}{*}{ : } & Static / Dynamic & static & \multicolumn{5}{|c|}{ dynamic } \\
\hline & Content & $\begin{array}{l}\text { location, capacity, } \\
\text { services, operator of } \\
\text { parking facilities, etc. }\end{array}$ & free capacities & actual travel times & $\begin{array}{c}\text { expected travel times } \\
\text { and / or expected } \\
\text { free capacity }\end{array}$ & $\begin{array}{c}\text { comprehensive, real- } \\
\text { time parking and traffic } \\
\text { information based on } \\
\text { forecasted data } \\
\end{array}$ & $\begin{array}{l}\text { comprehensive, real- } \\
\text { time centralized } \\
\text { route guidance }\end{array}$ \\
\hline & $\begin{array}{c}\text { Communication } \\
\text { channel }\end{array}$ & $\begin{array}{c}\text { leaflets, flyers, } \\
\text { brochures, handbooks, } \\
\text { internet, static road } \\
\text { signs, etc. }\end{array}$ & \multicolumn{2}{|c|}{$\begin{array}{l}\text { roadside variable message signs, } \\
\text { internet based applications (one way } \\
\text { communication) }\end{array}$} & $\begin{array}{c}\text { smartphone } \\
\text { applications (one } \\
\text { way communication) }\end{array}$ & $\begin{array}{c}\text { smartphone application } \\
\text { (two way } \\
\text { communication) }\end{array}$ & $\begin{array}{l}\text { user or vehicle } \\
\text { device (two way } \\
\text { communication) }\end{array}$ \\
\hline & Covered area & not specific & \multicolumn{2}{|c|}{ following one or more facilities } & \multicolumn{3}{|c|}{ motorway sections or networks } \\
\hline \multirow{5}{*}{ 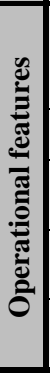 } & $\begin{array}{l}\text { Update } \\
\text { frequency }\end{array}$ & rarely & event controlled & \begin{tabular}{|c|} 
sampling time cycle \\
is $5-10$ min for \\
travel times
\end{tabular} & $\begin{array}{c}\text { in every } 5-10 \\
\text { minutes for forecast }\end{array}$ & $\begin{array}{l}\text { real-time even } \\
\text { bookings }\end{array}$ & real-time \\
\hline & Forecast horizon & \multicolumn{3}{|c|}{ not available } & \multicolumn{2}{|c|}{ app. $15-60$ minutes } & even 24 hours \\
\hline & $\begin{array}{c}\text { Location-based } \\
\text { services }\end{array}$ & \multicolumn{3}{|c|}{ not available } & \multicolumn{2}{|c|}{ based on cellular network } & satellite \\
\hline & Route planning & \multicolumn{4}{|c|}{ not available } & $\begin{array}{l}\text { previous + route } \\
\text { guidance software }\end{array}$ & $\begin{array}{l}\text { centrally, based on } \\
\text { user preferences }\end{array}$ \\
\hline & Booking & \multicolumn{4}{|c|}{ not available } & manually & $\begin{array}{l}\text { automatically with } \\
\text { route planning }\end{array}$ \\
\hline & Example & $\begin{array}{c}\text { Printed: IRU Truck } \\
\text { parking areas } \\
\text { handbook } \\
\text { Web: IRU TransPARK } \\
\text { www.iru.org }\end{array}$ & $\begin{array}{c}\text { On the spot: } \\
\text { French A13 } \\
\text { motorway } \\
\text { Web: Rheinland- } \\
\text { Pfalz } \\
\text { verkehr.rlp.de }\end{array}$ & \begin{tabular}{|c|} 
On the spot: \\
Germany, A3 \\
motorway \\
(Frankfurt) \\
Web: Traffic \\
Scotland \\
trafficscotland.org \\
\end{tabular} & $\begin{array}{c}\text { Web: Bayern Info } \\
\text { www.bayerninfo.de }\end{array}$ & $\begin{array}{c}\text { Germany, } \\
\text { Highway Park } \\
\text { www.highway-park.de }\end{array}$ & $\begin{array}{c}\text { this service is not yet } \\
\text { available }\end{array}$ \\
\hline
\end{tabular}




\section{Structure of the Parking Management System}

The main components (elements, subsystems) of a complex, integrated parking management system are:

- Users: truck drivers and/or haulier companies with their own preferences, parking booking demands; with personal devices that support two-way communication. This equipment can be applied as on-board units as well, e.g., navigation devices, smart phones, palmtops, laptops, (even PCs);

- Trucks: may have on-board computers that provide two-way communication and positioning. $\mathrm{OBUs}^{3}$ can replace personal devices.

- Motorway networks: with human (road operator dispatcher) and machine components. The latter ones include: automatic traffic and environment detectors (traffic counting stations, $\mathrm{CCTVs}^{4}$ with license plate recognition, weather stations, air pollution sensors, etc.), roadside information devices $\left(\mathrm{VMSs}^{5}\right.$, displays) and communication equipment.

- Parking facilities: with human (dispatcher, security guard) and machine components. The latter ones include: devices for data acquisition [occupancy detectors, ultrasonic sensors, vehicle identification and surveillance systems, etc.], devices for local data procession, devices for information provision [VMSs, displays, road markers, etc.] and communication equipment. Image processing and identification equipments (CCTV cameras, licence plate recognition), access control systems. In certain cases the human component may be omitted, for example when the facility can operate without direct human supervision.

- Parking management centre: contains human (operator) and machine components. It processes the incoming data and determines the information transmitted to devices for information provision. One centre can supervise one region or even one country. Centres are located close to other traffic management centres or may even be a part of them.

\footnotetext{
on-board unit

Closed-circuit television

Variable Message Sign
} 
Information terminals:

- Mobile devices: personal and/or vehicle on-board devices with their own operating systems (iOS, Android, Symbian, etc.), with multi-channel communication units (GPS, GSM, Wi-Fi, etc.), and with route planning and navigation programs that provide personalized, real-time information and parking place booking.

- Immobile devices: road traffic signs, variable message signs, controllable displays, LED markers at parking lots (lighting equipment or controllable prisms built in the road surface).

The listed elements are connected in the indicated relations by telecommunication channels (wired or wireless data networks). A continuous line indicates wired communication, and broken lines indicate wireless communication. The structure of the system is illustrated in Figure 2. The figure corresponds with the build-up of the highest service level. In the case of the lower levels, certain components are to be omitted. Only one element of each component is represented.

\section{Operation of the Parking Management System}

The most important objectives of parking management and route planning are [2], [4], [12]:

- the optimization of the capacity utilization of parking places,

- low time consumption (for parking place searching, entrance and exit), reliable, calculable and predictable travel time,

- the decrease of unnecessary travel distances and emissions, and the mitigation of noise pollution,

- a decrease in stress, an increase in user comfort,

- a decrease in the risk of accidents,

- the protection of vehicles,

- the maximizing of driving times while considering the generic rules,

- the minimizing of travel costs (overrun costs, facility usage fees, etc.).

The operational processes of the telematics system are summarized in Figure 3, which is coherent with the structural architecture. Arrows indicate the direction of data transfers. The figure corresponds with the operation of the highest service level. At lower levels, certain functions are not available; however, at higher levels the management system provides network management functions as well. Table 2 contains a description of certain operations. Level "4" and level "5" realize closed-loop control because real-time information provision (parking place booking and navigation) feeds back to the users' pre-trip decisions and thus influences demand. 


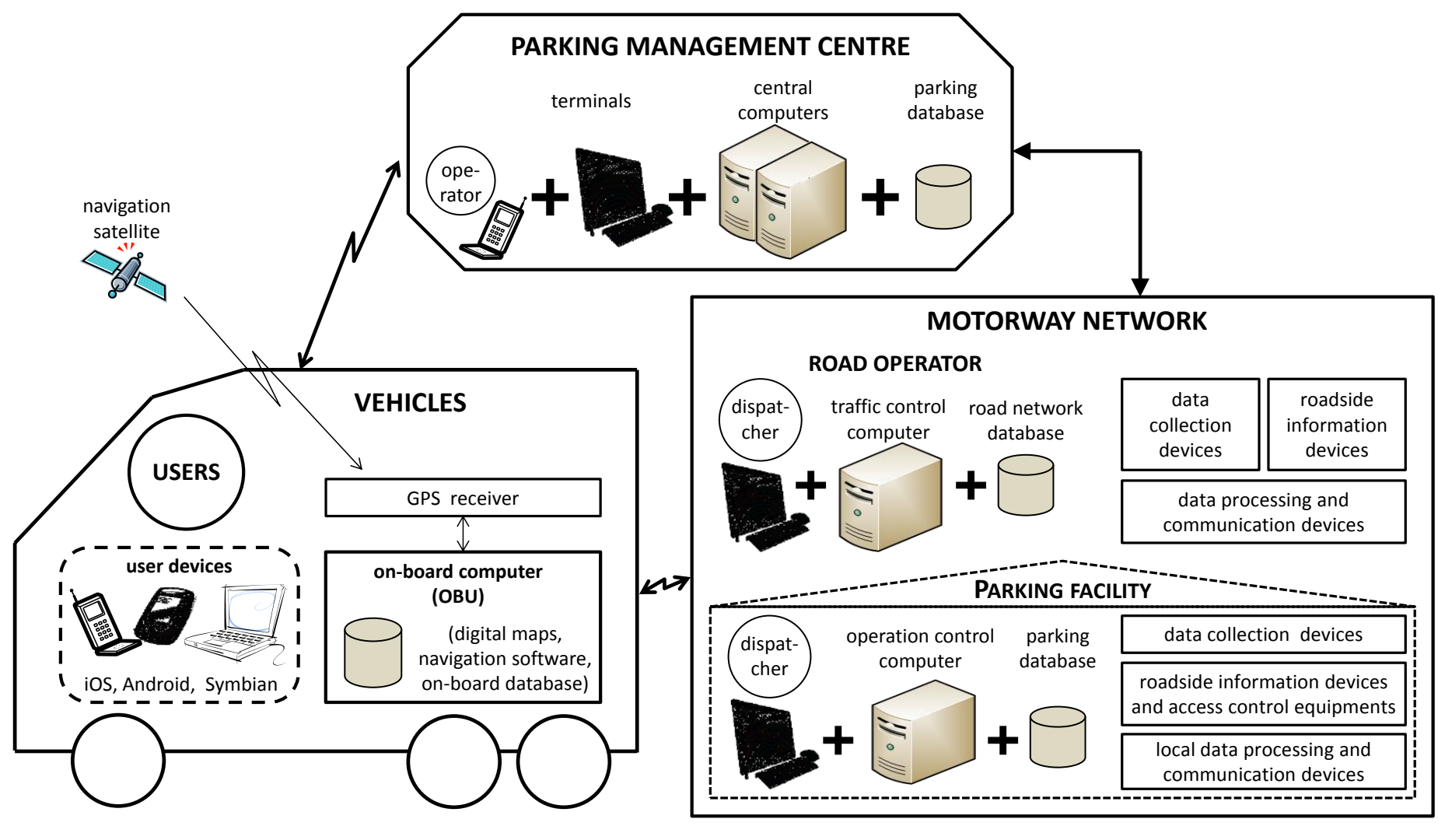

Figure 2

Structure of the integrated parking management system 


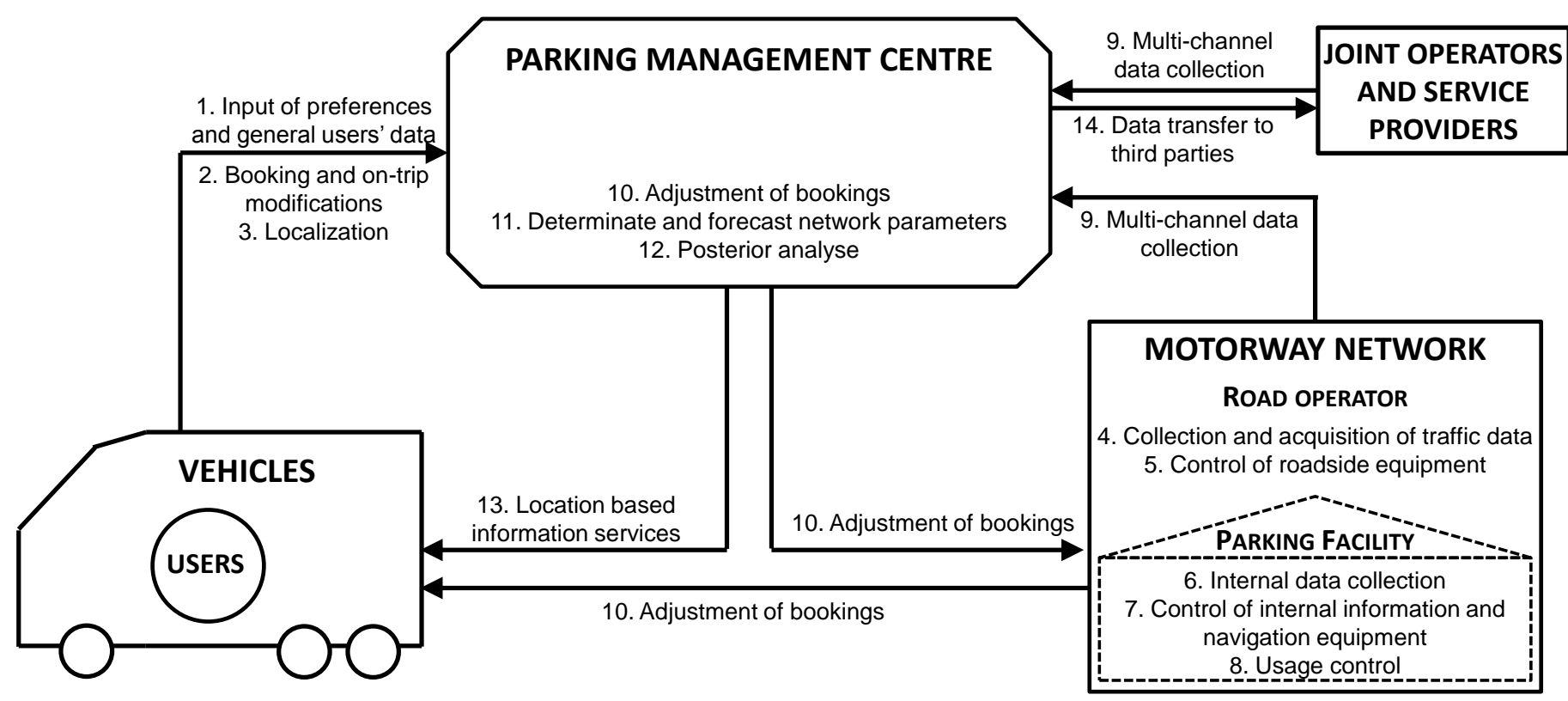

Figure 3

Operation model of the integrated parking management system 
Every user has their own user account at the parking management centre. Before route planning, they $\log$ in and record every route specific preference in connection with the given journey. During route planning, the incoming demands are assigned to the parking facilities, taking personal preferences and actual traffic parameters into consideration (departure time, route, driving times, stop-points, services for sale). The users are in contact with the management centre, and they transmit all such data to it. Booking records are confirmed by the parking facility and the management centre as well, so it is the only case when users get information in addition to that from the management centre. The route and the bookings can be modified based on actual conditions and the vehicle position.

Vehicles can be identified by their licence plates at the facilities. The data is also used to control facility usage, and it is possible to control driving times with or without the tachograph.

There is hierarchical data storage with duplicated/multiplied data elements. Data are stored in the management centre and also in the facilities. Facilities receive only the parking-related information about the users. Road operators do not have any route-specific information about the users and vehicles. Parking facilities are controlled by the parking management centre, but they are can operate autonomously. The management centre and some special parking facilities can be operated with non-stop human supervision.

During parking place selection, drivers take the following factors with decreasing importance into consideration: [9]

- $\quad$ Security;

- $\quad$ Previous own experiences;

- $\quad$ Additional services of the facility (e.g. sanitary facilities, catering, grocery shopping, petrol station, ATM, etc.);

- $\quad$ The number of available parking places.

Personalized parking place booking and intelligent parking management with dynamic navigation are value-added services. Thus, service providers may impose service fees and sanctions to motivate to the proper use (vehicle arrives in time, cancel bookings in time, etc.). The incurred expenses are paid on the spot or based on contracted agreements. 
Table 2

Parking-related information management operations

\begin{tabular}{|c|c|c|c|c|}
\hline \multicolumn{2}{|c|}{$\begin{array}{l}\text { groups of } \\
\text { operation }\end{array}$} & o. & name & escription \\
\hline \multirow{3}{*}{ 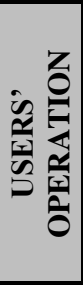 } & \multirow[t]{2}{*}{ 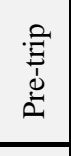 } & 1 & $\begin{array}{l}\text { Input of preferences } \\
\text { and general users' } \\
\text { data }\end{array}$ & $\begin{array}{l}\text { Input of data regarding customers, vehicles and } \\
\text { personal preferences. Record static data regarding route } \\
\text { and route-specific personal preferences. }\end{array}$ \\
\hline & & 2 & $\begin{array}{l}\text { Booking and on-trip } \\
\text { modifications }\end{array}$ & $\begin{array}{l}\text { Route planning and booking/parking place selection } \\
\text { according to personal preferences and actual traffic } \\
\text { situation. Modifications during journeys. }\end{array}$ \\
\hline & 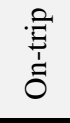 & 3 & Localization & $\begin{array}{l}\text { Transmitting current vehicle position to the information } \\
\text { management centre. }\end{array}$ \\
\hline \multirow{2}{*}{ 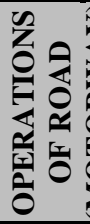 } & \multirow{2}{*}{ 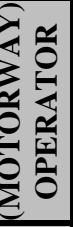 } & 4 & $\begin{array}{l}\text { Collection and } \\
\text { acquisition of } \\
\text { traffic data }\end{array}$ & $\begin{array}{l}\text { Measurement of traffic, weather and air pollution } \\
\text { parameters. }\end{array}$ \\
\hline & & 5 & $\begin{array}{r}\text { Control of } \\
\text { equipr }\end{array}$ & and forecasted travel \\
\hline \multirow{3}{*}{\multicolumn{2}{|c|}{ 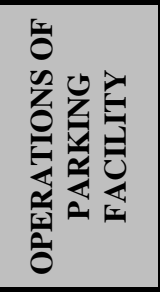 }} & 6 & $\begin{array}{r}\text { Intern } \\
\text { colle } \\
\end{array}$ & $\begin{array}{l}\text { Acquirement of actual occupancy data, identification } \\
\text { of entering and exiting vehicles. }\end{array}$ \\
\hline & & 7 & $\begin{array}{l}\text { Control of internal } \\
\text { equipment }\end{array}$ & $\begin{array}{l}\text { Operation of facility information and navigation } \\
\text { displays, VMSs and lighting equipment built in the } \\
\text { road surface. }\end{array}$ \\
\hline & & 8 & Usag & $\begin{array}{l}\text { Monitoring users and operation of safety \& security } \\
\text { equipment (e.g. access control and image processing } \\
\text { systems). }\end{array}$ \\
\hline \multirow{6}{*}{ 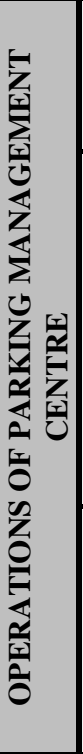 } & 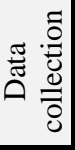 & 9 & $\begin{array}{r}\text { Multi-chan } \\
\text { collect }\end{array}$ & $\begin{array}{l}\text { Data come from several automatic data collector } \\
\text { elements (from traffic counting stations, weather } \\
\text { stations, occupancy detectors, etc.). Data from joint } \\
\text { operators and service providers are also incoming data. }\end{array}$ \\
\hline & \multirow{3}{*}{ 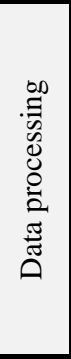 } & 10 & $\begin{array}{l}\text { Adjustment of } \\
\text { bookings }\end{array}$ & $\begin{array}{l}\text { Procession of incoming travel and parking demands; } \\
\text { assignment of free parking lots to booking demands. }\end{array}$ \\
\hline & & 11 & $\begin{array}{l}\text { Determinate and } \\
\text { forecast network } \\
\quad \text { parameters }\end{array}$ & $\begin{array}{l}\text { Determinate actual network parameters based on } \\
\text { incoming traffic parameters (free parking capacity, } \\
\text { travel times). Determinate expectable travel times and } \\
\text { free parking capacity based on actual traffic } \\
\text { parameters and historical data. (Forecast horizon } \\
\text { depends on the applied algorithm.) }\end{array}$ \\
\hline & & 12 & Posterior analyse & $\begin{array}{l}\text { s' behaviour and } \\
\text { and traffic predictions. }\end{array}$ \\
\hline & \multirow[t]{2}{*}{ 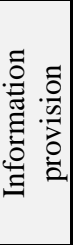 } & 13 & $\begin{array}{l}\text { Location based } \\
\text { information } \\
\text { services }\end{array}$ & $\begin{array}{l}\text { Real-time route guidance and navigation for vehicles } \\
\text { with combination of individual and system optimum } \\
\text { (dynamic modification of released route plan and } \\
\text { automatic rebooking), emergency management. } \\
\text { Control of user and vehicle (OBU) equipment. }\end{array}$ \\
\hline & & 14 & $\begin{array}{l}\text { Data transfer to } \\
\text { third parties }\end{array}$ & $\begin{array}{l}\text { Data sharing and transfer to joint operators and service } \\
\text { providers. }\end{array}$ \\
\hline
\end{tabular}


The main task of the parking management system is to redirect the exceeding demands automatically to previous or - when driving time allows it - following facilities by taking driving times and user preferences into consideration. When it is not possible, demands can be realigned by changing departure times. The management system can modify only pre-planned parking demands. It does not have any effect on ad hoc users and those who do not have a booking. They can be influenced by roadside occupancy information. The service offers secondary, complementary guidance for trucks via the transmission of traffic and parking related information (Dispatchers from the transport company give the primary guidance via the completion of route plans).

At the top level of service, complex traffic management centres will be established, where all traffic, parking and transportation related information are available. Management centres can serve comprehensive traffic management and information provision tasks as well based on the available data. The traffic management system can handle emergencies (it alerts the emergency services, coordinates the rescue, provides real-time traffic control and management, etc.), provides real-time information for vehicle drivers, and if necessary - after user acceptance -makes changes automatically related to alternative routes.

\section{Implementation Possibilities}

The opportunities for such a complex information provision system can be fully realized when services are developed in an interoperable way, allowing the latter network connection for further operators. The use of a common data structure (e.g. DATEX $\mathrm{II}^{6}$ ) supports the former aims and the harmonized information provision, as well as cross border operation. The partners of the EasyWay consortium established by the EU - are currently developing their own parking information services, but these project are only in the pilot phase and the questions of cross border data transmission are still open [15].

It is an obvious solution to provide information via on-board equipment that is already built-in. Devices of satellite-based tracking (GPS, GNSS ${ }^{7}$ ) electronic fee toll collection systems are well-suited for these solutions that can realize location based services and further information provision services in an integrated manner.

In Hungary, the parking management system would have the greatest impact on the $4^{\text {th }}$ corridor of the Trans-European Transport Network (M1-M5 motorways) where transit and freight transport is greatest. Capacity utilization of the parking areas would be better. Parking needs can be allocated according to supply and

6 DATa EXchange - improves data exchange between countries and organisations

Global Navigation Satellite System 
demand. Nowadays in Hungary the implementation of a satellite-based electronic fee toll collection system is quite current. During the system design, experts should endeavour to create and realize a complex toll collection system that is appropriate for other functions as well, like the dissemination of traffic and parking related information.

\section{Conclusion}

The route planning of trucks includes also the planning of parking, and parking management must be a part of traffic management. The intelligent parking management system for trucks is a rather new solution for traffic control and information provision services, as part of intelligent transport systems. The feasibility and the benefit of this service has been analysed in several studies and pilot projects. With advanced information provision, capacity utilization can be improved and, at the same time, congestions can be avoided. All of these require investments mainly in the information infrastructure, not in the parking facilities themselves. The information system supports the better capacity utilization by demand and capacity assignment. As every ITS application, this service also allows for better traffic circulation without significant infrastructure investment by detailed information services. Parking management systems allow for minimizing traffic searching for parking places, and the services contribute to more efficient and effective route planning and driving.

The main contribution of the article is the creation of a model including $5+1$ service levels. It outlines the future incremental developments. For the top service level, detailed structural and operational models have been elaborated. The presented integrated information system provides comprehensive, central navigation that supports every participant of the transport and haulier sector. The drivers' work becomes safer and more comfortable, while the supply chain becomes more predictable.

\section{References}

[1] COM (2008) 886 Action Plan for the Deployment of Intelligent Transport Systems in Europe. Brussels 2008

[2] Core European ITS Services and Actions: Guideline for the deployment of Intelligent Truck Parking, 2010

[3] Directive 2010/40/EU of the European Parliament and of the Council, on the Framework for the Deployment of Intelligent Transport Systems in the Field of Road Transport and for Interfaces with other Modes of Transport, Brussels, 2010

[4] Freight \& Logistics Services: Intelligent Truck Parking and Secure Truck Parking. Deployment guideline, FLS-DG01, Version 01-02-00, Jan. 2012 
[5] Gongjun, Yan: SmartParking - A Secure and Intelligent Parking System. Intelligent Transportation Systems Magazine, Vol. 3, Issue 1, pp. 18-30, 2011

[6] Real-Time Dynamic Information Services 2009, Action Plan for the RealTime Dynamic Information System on Motorway M1, EasyWay Project cofinanced by TEN-T, Project Number: 2007-EU-50010-P

[7] Real-Time Dynamic Information Services/Development of the Monitoring System of Parking Areas, Occupancy Monitoring, Suggestions, Navigation, etc / for the Heavy Goods Transport on the Main Road Corridors, Feasibility Study, EasyWay Project co-financed by TEN-T, Project Number: 2007-EU-50010-P

[8] Regulation EC No 561/2006 of the European Parliament and of the Council, on the Harmonisation of Certain Social Legislation Relating to Road Transport, Brussels, 2006

[9] Sándor, Zsolt - Nagy, Enikő: Development Possibilities of the Intelligent Truck Parking System in Hungary. TDK paper, BME, Department of Transport Technology, Budapest, 2011

[10] Sándor, Zsolt - Nagy, Enikö: Foreign Solution for the Area of Intelligent Truck Parking and National Application Possibility. Conference edition IFFK-2011(Paper 42), ISBN 978-963-88875-3-5 and 978-963-88875-2-8

[11] Sándor, Zsolt - Nagy, Enikő: Intelligent Truck Parking on the Hungarian Motorway Network. Pollack Periodica, Vol. 7, No. 2, August 2012

[12] Secured Truck Parking in Europe. ITP Workshop, Montabaur, 07.08.11.2010

[13] Szabó, Péter: Observing Possibilities of the Rules of Driving Times on the Hungarian Motorway Network and Necessary Developments. Thesis work, BME, Department of Transport Technology, Budapest, 2010

[14] Freight \& Logistics Services: Intelligent Truck Parking and Secure Truck Parking. Deployment guideline, FLS-DG01, Version 02-00-00, Dec. 2012 